\title{
Análise do texto "Negócio de menino com menina”, de O ladrão de sonhos e outros contos, de Ivan Ângelo
}

Vanessa de Paula ZAGNOLE

(Universidade Presbiteriana Mackenzie)

RESUMO: O objetivo deste trabalho é verificar os três níveis do percurso gerativo do sentido, proposto pela semiótica francesa, no conto "Negócio de menino com menina", do livro O ladrão de sonhos e outros contos, de Ivan Ângelo.

PALAVRAS CHAVE: manipulação; percurso gerativo; plano de conteúdo

ABSTRACT: The aim of this paper is to verify the three levels of the generative process on the short story "Negócio de menino com menina", by Ivan Ângelo. Such short story is in the book $\mathrm{O}$ ladrão de sonhos e outros contos.

KEYWORDS: manipulation; generative process; plane of contents 


\section{NíveL NARRATIVo}

Os enunciados narrativos podem ser de dois tipos: de estado e de transformação. As relações entre os sujeitos e objetos podem ser de conjunção e/ou disjunção. Sempre haverá ao menos um enunciado de estado e um de transformação para que aconteça o programa narrativo.

Os percursos narrativos são organizações em que pelo menos um enunciado de transformação opera sobre os enunciados de estado de conjunção ou disjunção.

No primeiro parágrafo do texto, há três enunciados de estado, sendo eles: i) em que o sujeito (menino) está em conjunção com o objeto (passarinho); ii) em que o sujeito (menina) está em disjunção com o objeto (passarinho) e iii) em que o sujeito (pai) está em conjunção com o objeto (fazenda), pois é o seu novo dono.

O menino, de uns dez anos, pés no chão, vinha andando pela estrada de terra da fazenda com a gaiola na mão. Sol forte de uma hora da tarde. A menina, de uns nove anos, ia de carro com o pai, novo dono da fazenda. Gente de São Paulo. Ela viu o passarinho na gaiola e pediu ao pai: - Olha que lindo! Compra pra mim? ${ }^{1}$

Há também a presença do enunciado de transformação, em que o sujeito (menina) procura transformar a relação de conjunção do sujeito (menino) com o objeto (passarinho) em relação de disjunção: "Ela viu o passarinho na gaiola e pediu ao pai: — Olha que lindo! Compra pra mim?”.

Segundo Barros (2005), assim é montado o espetáculo com as personagenssujeito e objeto e a relações entre elas, de elasticidade e dinamicidade.

No programa supracitado, se um sujeito adquire um valor é porque outro provavelmente é privado ou dele se priva.

No texto analisado, há o que se chama de aquisição transitiva por doação. O sujeito menina parece conseguir o objeto de valor passarinho, doado pelo sujeito menino. E por outro lado, há também uma privação reflexiva por renúncia, pois o sujeito menino resolve doar o objeto de valor passarinho.

O menino chegou pertinho da menina e falou baixo, só pra ela ouvir:

- Amanhã eu dou ele pra você.

Ela sorriu e compreendeu.

\section{Percurso da Manipulação}

O percurso da manipulação se dá quando um destinador propõe a um destinatário um contrato, que objetiva levá-lo a fazer alguma coisa. Para isso, é necessária a persuasão. Pode-se exemplificar a grande manifestação da manipulação em "Negócio de menino com menina”, por meio do seguinte quadro: 


\begin{tabular}{|l|l|l|}
\hline & $\begin{array}{l}\text { Competência do destinador- } \\
\text { manipulador }\end{array}$ & $\begin{array}{l}\text { Alteração na } \\
\text { competência do } \\
\text { destinatário }\end{array}$ \\
\hline Provocação & $\begin{array}{l}\text { SABER (imagem negativa do } \\
\text { destinatário) }\end{array}$ & DEVER-FAZER \\
\hline Sedução & $\begin{array}{l}\text { SABER (imagem positiva do } \\
\text { destinatário) }\end{array}$ & $\begin{array}{l}\text { QUERER- } \\
\text { FAZER }\end{array}$ \\
\hline Intimidação & PODER (valores negativos) & DEVER-FAZER \\
\hline Tentação & PODER (valores positivos) & $\begin{array}{l}\text { QUERER- } \\
\text { FAZER }\end{array}$ \\
\hline
\end{tabular}

Na estrutura narrativa de "Negócio de menino com menina”, tem-se a intensa e propositada presença dos quatro tipos de manipulação. O destinador filha, enfatizando o atributo de conquistador "quem pode tudo" do destinatário pai, manipula-o para que ele tente adquirir o objeto de valor passarinho:

\section{Manipulação por sedução}

Ela viu o passarinho na gaiola e pediu ao pai: — Olha que lindo! Compra pra mim? [...] O pai olhou para a filha com uma cara de deixa pra lá. A filha pediu suave como se o pai tudo pudesse:

— Fala pra ele vender.

[...]

A filha, baixinho, indiferente às possibilidades da transação:

— Mas eu queria. Olha que bonitinho.

Sendo assim, o destinador filha procura transformar a competência do destinatário pai, levando-o a querer-fazer (querer comprar) o objeto passarinho.

O destinatário pai recebe o valor modal de querer-fazer, querer comprar o objeto passarinho, logo ocupa a posição de destinador e passa a persuadir o destinatário menino, oferecendo-lhe, por várias vezes, quantia em dinheiro pelo objeto passarinho.

\section{Manipulação por tentação}

O pai, mais para atendê-la, apenas intermediário:

— Quanto você quer pelo passarinho?

[...]

— Dou dez mil.

- Não senhor.

- Vinte mil.

— Vendo não.

O homem meteu a mão no bolso, tirou o dinheiro, mostrou três notas, irritado.

— Trinta mil.

— Não tou vendendo, não, senhor.

O homem resmungou "que menino chato" e falou pra filha:

[...]

— Dou quarenta mil, pronto. Toma aqui. 
- Não senhor, muito obrigado.

O homem, meio mandão:

— Vende isso logo, menino. Não tá vendo que é pra menina?

— Não, não tou vendendo não.

O destinador pai percebe que o destinatário menino não abre mão do passarinho e resolve mudar sua tática persuasiva mais uma vez, depreciando o objeto de valor passarinho:

\section{Manipulação por provocação}

— Qual é o nome deste passarinho?

— Ainda não botei nome nele, não. Peguei ele agora.

O homem quase impaciente:

— Não perguntei se ele é batizado não, menino. É pintassilgo, é sabiá, é o que?

— Aaaah. É bico-de-lacre.

A menina pela primeira vez, falou com o menino:

— Ele vai crescer?

O menino parou os olhos pretos nos azuis.

- Cresce nada. Ele é assim mesmo, pequenininho.

O homem:

- E canta?

- Canta nada. Só faz chiar assim.

- Passarinho besta, hein?

— É. Não presta pra nada, é só bonito.

Não obtendo êxito, o destinador pai muda mais uma vez a forma de persuasão e passa a provocar o destinatário menino, dizendo-lhe que o passarinho foi pego na fazenda, logo, pertence a ele.

\section{Manipulação por intimidação:}

— Você pegou ele dentro da fazenda?

- É. Aí no mato.

— Essa fazenda é minha. Tudo que tem nela é meu.

O menino segurou com mais força a alça da gaiola, ajudou com a outra mão nas grades. O homem achou que estava na hora e falou já botando a mão na gaiola, dinheiro na outra mão.

$[\ldots]$

O homem, meio mandão:

— Vende isso logo, menino. Não tá vendo que é pra menina?

Num dado momento do texto, o destinador menina também manipula o destinatário menino, assim, o destinatário menino resolve querer-fazer (querer-dar) o objeto de valor passarinho ao destinador menina. 


\section{Percurso da Ação}

O percurso da ação se organiza em dois programas narrativos que são o de performance e de competência.

Barros (2005) considera o programa narrativo de performance como sendo formado a partir de uma transformação de um estado de disjunção em um estado de conjunção, operada por um sujeito transformador que é realizado pelo mesmo ator do sujeito que tem seu estado transformado.

Em "Negócio de menino com menina", o programa narrativo de performance é realizado pelo sujeito menina, que transforma seu estado de disjunção com o objetovalor passarinho em estado de conjunção.

O menino chegou pertinho da menina e falou baixo, só pra ela ouvir:

- Amanhã eu dou ele pra você.

Ela sorriu e compreendeu.

Para Barros (2005), o programa narrativo de competência do sujeito transformador é realizado por um ator diferente do sujeito de estado, e o valor do objeto é um valor modal, isto é, um valor necessário para que o sujeito obtenha, na performance, o valor descritivo último desejado. O sujeito transformador menino entra em conjunção com o valor modal querer-fazer, querer doar.

O menino chegou pertinho da menina e falou baixo, só pra ela ouvir:

— Amanhã eu dou ele pra você.

\section{Percurso da Sanção}

É neste percurso que o destinador vai dar ao destinatário o reconhecimento pelo cumprimento ou não do acordo e a retribuição ou a punição.

No texto em questão, há três fases da sanção. Num primeiro momento, a persuasão do pai não foi bem sucedida. Apesar do pai ser “[...] um homem de negócios, águia da Bolsa, acostumado a encorajar os mais hesitantes ou a virar a cabeça dos mais recalcitrantes”, a sanção foi negativa por parte do menino à manipulação feita pelo destinador pai.

— Não senhor.

[...]

— Não tou vendendo não senhor.

[...]

- Não senhor.

[...]

— Vendo não.

[...]

— Não tou vendendo, não, senhor.

$[\ldots]$

— Não senhor, muito obrigado.

[...] 
— Não, não tou vendendo não.

[...]

— Quero não senhor. Tou vendendo não.

O pai também sanciona negativamente não só o menino, mas sua condição e classe social:

O homem resmungou que menino chato [...].

O homem voltou para o carro, nervoso. Bateu a porta, culpando a filha pelo aborrecimento.

— Viu no que dá mexer com essa gente? É tudo ignorante, filha. Vam’bora.

Os sistemas de valores do destinatário menino e do destinador pai são diferentes, por este motivo a manipulação não funciona. Enquanto o destinador pai tenta manipulá-lo com valor monetário, o verdadeiro objeto de valor para o filho é o passarinho.

Já num terceiro momento, a sanção do menino à manipulação feita pela menina se dá de forma positiva, pois o menino parece querer doar o objeto de valor passarinho à menina:

O menino chegou pertinho da menina e falou baixo, só pra ela ouvir:

- Amanhã eu dou ele pra você.

Ela sorriu e compreendeu.

Segundo (Barros, 2005), a modalização veridictória relaciona-se ao fazer interpretativo, examinado nas manipulações. Diz respeito também à modalização do ser, a determinação pelas modalidades do querer, saber, dever, poder da relação do sujeito com os valores. Esse tipo de modalização altera a existência modal do sujeito. No texto, a relação do menino e o passarinho é modificada, pois o menino não queria vender o passarinho (“- Esse passarinho é para vender? - Não senhor.”) e, depois da manipulação por sedução feita pela menina, ele passa a querer doar o passarinho.

$$
\begin{aligned}
& 1^{\circ} \text { - antes da menina } \\
& \text { "não queria vender" }
\end{aligned} \quad \Rightarrow \quad \begin{array}{r}
2^{\circ} \text { - depois da menina } \\
\text { "querer doar" }
\end{array}
$$

Quanto às modalidades veridictórias, o pai parecia ser um grande negociador “[...] o pai era um homem de negócios, águia da Bolsa, acostumado a encorajar os mais hesitantes ou a virar a cabeça dos mais recalcitrantes”, mas não consegue convencer o menino a vender o passarinho, a partir disso, configura-se modalidade veridictória da mentira.

O menino, por sua condição, parecia ser inocente e fácil de ser manipulado por dinheiro, porém não se deixa persuadir, o que configura a modalidade veridictória da falsidade. 
Já a menina, que não parecia ser uma negociante, por não ter a experiência e a competência do pai, consegue fechar o negócio, configurando-se, então, a modalidade veridictória da verdade.

O menino, que não parecia querer desfazer-se do passarinho, firma um acordo secreto com a menina e diz que doará o passarinho sem que o pai ouça, configurando-se a modalidade veridictória do segredo.

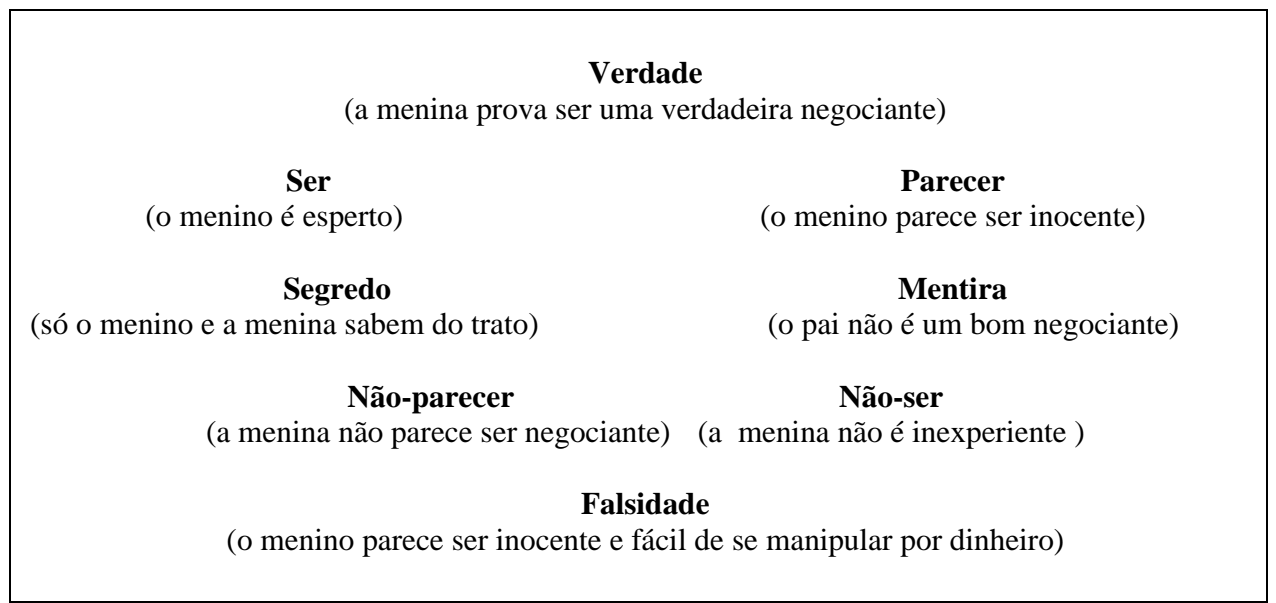

Quanto às modalidades actualizantes e virtualizantes, o pai da menina é um sujeito virtual, pois quer ou deve fazer alguma coisa para obter o objeto de valor passarinho para sua filha. Já a menina é o sujeito atualizado, que após realizar o fazer e adquirir por conjunção o objeto de valor passarinho, passa a ser um sujeito realizado.

Segundo Barro (2005) as paixões, nos textos são efeitos de sentido de organizações de modalidades, moduladas pela continuidade da tensão e do relaxamento.

Em "Negócio de menino com menina", tem-se a paixão da frustração, decorrente de o pai, apesar de possuir meios para isto, não conseguir obter o valor desejado. Porém, o percurso passional do texto é contínuo, que vai desta mesma tensão e frustração por parte do pai de não obter o objeto à alegria e satisfação relaxadas, por parte da filha, de poder obtê-lo.

\section{NívEL DISCURSIVO}

É neste nível que as formas abstratas do nível narrativo são revestidas de termos que lhes dão maior concretude, segundo Fiorin (2005).

O texto é constituído por desembreagem enunciva para produzir um efeito de distanciamento da enunciação, com o emprego da terceira pessoa "ele", do tempo "então" e do espaço "lá”. O espaço do lá é figurativizado como a fazenda:

O menino, de uns dez anos, pés no chão, vinha andando pela estrada de terra da fazenda com a gaiola na mão. Sol forte de uma hora da tarde. A menina, de uns nove anos, ia de carro com o pai, novo dono da fazenda. 
O tempo do então é figurativizado no texto como: "Sol forte de uma hora da tarde”.

Em “Negócio de menino com menina”, há presença do que Barros (2005) chama de "simulacro da realidade", por conta do arranjo de pessoa do discurso, como por exemplo, em: "Ela viu o passarinho na gaiola e pediu ao pai: — Olha que lindo! Compra pra mim?”, em que acontece uma desembreagem interna, pois a voz é dada internamente a um outro ator. $\mathrm{O}$ uso desse tipo de desembreagem traz ao texto um certo efeito de realidade ou referente.

A tematização e a figuratização, segundo Barros (2005), correspondem ao “enriquecimento" semântico do discurso. Na tematização ocorre a disseminação no discurso dos traços semânticos tomados de forma abstrata. Já na figuratização, esses traços semânticos tomados de forma abstrata são "recobertos" por traços semânticos "sensoriais" que lhes dão o efeito de concretização sensorial.

"Negócio de menino com menina” trata-se de um texto temático-figurativo. Um dos temas possíveis é o socioeconômico sobre a vida humilde de famílias que vivem em fazendas não como donos, e sim como empregados. A oposição semântica ligada a este tema é pobreza vs riqueza. É possível perceber traços semânticos de pobreza em: "pés no chão, roupa encardida, com um rasgo na manga, vermelho do sol, olhos pretos, voz trêmula, com fome e com sede, ignorante”. Já os traços semânticos de riqueza ficam evidentes em: “[...] ia de carro, dono da fazenda, gente de São Paulo, homem de negócios, águia da Bolsa, essa fazenda é minha”, entre outros.

A pobreza e a riqueza são figurativizadas pelos seguintes traços sensoriais:

\begin{tabular}{|l|l|l|}
\hline & Pobreza & Riqueza \\
\hline Tátil & "pés no chão" & $\begin{array}{l}\text { "mão no bolso, } \\
\text { dinheiro na mão, }\end{array}$ \\
\hline Auditivo & "voz trêmula"- & "baixinho" \\
\hline Gustativo & "com fome e com sede"- & \multicolumn{2}{|c|}{} \\
\hline Visual & $\begin{array}{l}\text { "roupa encardida, com um } \\
\text { rasgo na manga, vermelho do } \\
\text { sol, olhos pretos, carinha de São } \\
\text { boa." }\end{array}$ & $\begin{array}{l}\text { Paulo, homem de } \\
\text { negócios, ia de } \\
\text { carro, olhos azuis, } \\
\text { cara de deixa pra } \\
\text { lá." }\end{array}$ \\
\hline
\end{tabular}

Outro tema possível de se observar é o da iniciação sexual, pois a menina começa a brincar com o passarinho na gaiola e estabelece um diálogo com o menino sobre o desenvolvimento do animal. O passarinho figurativiza o órgão sexual masculino com que a menina entra em contato pela primeira vez, e como diz o texto: "procurava intimidade com o passarinho, dedinho nas gretas da gaiola”. A oposição semântica é ingenuidade vs malícia.

Os traços de ingenuidade aparecem em: "Mas eu queria. Olha que bonitinho", “[...] procurava intimidade com o passarinho”, "Ele é assim mesmo, pequenininho”, “Canta nada”, "Não presta pra nada”, “A menina pela primeira vez, falou com o 
menino”. E os traços de malícia estão atrelados aos trechos: "Parou ao lado da janela da menina”; "Ele vai crescer?”, “O menino parou os olhos pretos nos azuis”; “Amanhã eu dou ele pra você”.

Barros (2005) considera que os discursos podem ter uma única isotopia ou serem pluri-isotópicos. É possível dizer que o próprio título do texto em análise é um conector de isotopia, quando a informação é que o negócio é de menino com menina e na maior parte do texto quem parece negociar com o menino é o pai. Além disso, o termo "passarinho" também é um desencadeador de isotopia, visto que a partir dele é possível se fazer uma nova leitura que é a da iniciação sexual.

$\mathrm{Na}$ análise do discurso, há ainda a etapa da iconização que produz efeitos de realidade e de referente. Esses efeitos são obtidos pelo procedimento de ancoragem do tempo, espaço e dos atores, em datas, lugares e pessoas que o destinatário do texto reconhece como reais. No texto em questão, há apenas a ancoragem de atores, em que há a revelação da idade, posição social, local onde moram e profissão:

O menino, de uns dez anos [...]. A menina, de uns nove anos, ia de carro com o pai, novo dono da fazenda. Gente de São Paulo. [...] Mas o pai era um homem de negócios, águia da Bolsa, acostumado a encorajar os mais hesitantes ou a virar a cabeça dos mais recalcitrantes [...].

\section{NÍVEL FUNDAMENTAL}

É o nível em que se determina o mínimo de sentido a partir de que o discurso se constrói. Nele é possível explicar o modo de existência da significação como uma estrutura em que a rede de relações se reduz a uma única relação. Trata-se da relação de oposição ou da "diferença" entre os dois termos, no interior de um mesmo eixo semântico que os engloba, pois o mundo não é diferença pura.

Em "Negócio de menino com menina”, a categoria semântica fundamental é civilização vs natureza, que se manifesta no texto de várias maneiras, mas que "resume", de forma simples e abstrata, o conteúdo geral do texto.

Percebe-se que o texto é euforizante, ou seja, que vai da disforia para a euforia, acaba bem. A resistência do menino em não querer abrir mão do passarinho é quebrada e ele passa a ter vontade de doá-lo a menina. Os termos resistência (disfórico) e vontade (eufórico) estão, respectivamente, para a categoria semântica fundamental civilização, que é o arrogante e forjado, e natureza, que é o simples e autêntico. Junto ao comportamento simples do menino e ao resultado da negociação entre ele e a menina está atrelada a categoria natureza, já a insistência e arrogância do pai está ligada à categoria civilização.

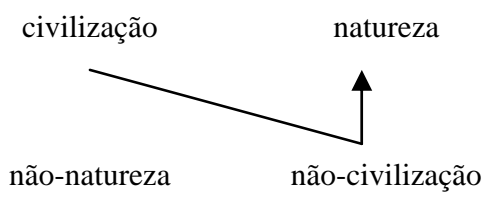


Ao longo da análise foram contemplados nos três níveis do texto os elementos internos e as relações de sentido no conto “Negócio de menino com menina”. Após todas as manipulações feitas pelo pai da menina, o sujeito menino deixa-se vencer pela delicadeza da menina e resolve doar o passarinho, eis o negócio do menino com a menina.

\section{Notas}

${ }^{1}$ Por se tratar de um conto de pequena extensão, optamos por não inserir, em cada entrada de trecho citado, as indicações de autor, data e número de página (o conto, em sua totalidade, se encontra em anexo, no final do presente artigo).

\section{REFERÊNCIAS BIBLIOGRÁFICAS}

ÂNGELO, Ivan. "Negócio de menino com menina”. In: O ladrão de sonhos e outros contos. São Paulo: Ática, 1995:10-11.

BARROS, Diana Luz Pessoa de. Teoria semiótica do texto. São Paulo: Ática, 2005.

FIORIN, José Luiz. Elementos de análise do discurso. São Paulo: Contexto, 2005. . Introdução à lingüística II - Princípios e análise. São Paulo: Contexto, 2005.

\section{ANEXo}

\section{Negócio de menino com menina}

O menino, de uns dez anos, pés no chão, vinha andando pela estrada de terra da fazenda com a gaiola na mão. Sol forte de uma hora da tarde. A menina, de uns nove anos, ia de carro com o pai, novo dono da fazenda. Gente de São Paulo. Ela viu o passarinho na gaiola e pediu ao pai:

- Olha que lindo! Compra pra mim?

O homem parou o carro e chamou:

- Ô menino.

O menino voltou, chegou perto, carinha boa. Parou ao lado da janela da menina. O homem:

- Esse passarinho é para vender?

- Não senhor.

O pai olhou pra filha com uma cara de deixa pra lá. A filha pediu suave como se o pai tudo pudesse:

- Fala pra ele vender.

O pai, mais para atendê-la, apenas intermediário:

- Quanto você quer pelo passarinho?

- Não tou vendendo não senhor.

A menina ficou decepcionada e segredou:

- Ah, pai, compra.

Ela não considerava, ou não aprendera ainda, que negócio só se faz quando existe um vendedor e um comprador. No caso, faltava o vendedor. Mas o pai era um 
homem de negócios, águia da Bolsa, acostumado a encorajar os mais hesitantes ou a virar a cabeça dos mais recalcitrantes:

- Dou dez mil.

- Não senhor.

- Vinte mil.

—Vendo não.

O homem meteu a mão no bolso, tirou o dinheiro, mostrou três notas, irritado.

- Trinta mil.

- Não tou vendendo, não, senhor.

O homem resmungou "que menino chato" e falou pra filha:

- Ele não quer vender. Paciência.

A filha, baixinho, indiferente às possibilidades da transação:

- Mas eu queria. Olha que bonitinho.

O homem olhou a menina, a gaiola, a roupa encardida do menino, com um rasgo na manga, o rosto vermelho do sol.

- Deixa comigo.

Levantou-se, deu a volta, foi até lá. A menina procurava intimidade com o passarinho, dedinho nas gretas da gaiola. O homem maneiro, estudando o adversário:

- Qual é o nome deste passarinho?

— Ainda não botei nome nele, não. Peguei ele agora.

O homem quase impaciente:

- Não perguntei se ele é batizado não, menino. É pintassilgo, é sabiá, é o que?

- Aaaah. É bico-de-lacre.

A menina pela primeira vez, falou com o menino:

- Ele vai crescer?

O menino parou os olhos pretos nos azuis.

- Cresce nada. Ele é assim mesmo, pequenininho.

O homem:

- E canta?

- Canta nada. Só faz chiar assim.

- Passarinho besta, hein?

- É. Não presta pra nada, é só bonito.

- Você pegou ele dentro da fazenda?

- É. Aí no mato.

- Essa fazenda é minha. Tudo que tem nela é meu.

O menino segurou com mais força a alça da gaiola, ajudou com a outra mão nas grades. O homem achou que estava na hora e falou já botando a mão na gaiola, dinheiro na outra mão.

- Dou quarenta mil, pronto. Toma aqui.

- Não senhor, muito obrigado.

O homem, meio mandão:

- Vende isso logo, menino. Não tá vendo que é pra menina?

- Não, não tou vendendo não.

- Cinqüenta mil! Toma! - e puxou a gaiola. 
Com cinqüenta mil se comprava um saco de feijão, ou dois pares de sapatos, ou uma bicicleta velha.

O menino resistiu, segurando a gaiola, voz trêmula.

- Quero não senhor. Tou vendendo não.

- Não vende por quê, hein? Por quê?

O menino acuado, tentando explicar:

- É que eu demorei a manhã todinha pra pegar ele e tou com fome e com sede, queria ter ele mais um pouquinho. Mostrar pra mamãe.

O homem voltou para o carro, nervoso. Bateu a porta, culpando a filha pelo aborrecimento.

- Viu no que dá mexer com essa gente? É tudo ignorante, filha. Vam `bora.

O menino chegou pertinho da menina e falou baixo, só pra ela ouvir:

- Amanhã eu dou ele pra você.

Ela sorriu e compreendeu.

Como citar este artigo:

ZAGNOLE, Vanessa de Paula. Análise do texto "Negócio de menino com menina", de O ladrão de sonhos e outros contos, de Ivan Ângelo. Estudos Semióticos. [online] Disponível na Internet via WWW.URL: http://www.fflch.usp.br/dl/semiotica/es. Editor Peter Dietrich. Número 4, São Paulo, 2008.

Acesso em "dia/mês/ano". 